\title{
Distinct Subcellular Localization of GSK-3 $\beta$ in Melanocytic Nevi: Implications in Melanocyte Senescence
}

\author{
Jonathan L. Curry ${ }^{1 \#}$, Carlos A. Torres-Cabala ${ }^{1}$, Carla L. Warneke ${ }^{2}$, Peter Zhang ${ }^{1}$, Victor G. Prieto ${ }^{1}$ \\ ${ }^{1}$ Departments of Pathology and Dermatology, The University of Texas MD Anderson Cancer Center, Houston, USA; ${ }^{2}$ Departments \\ of Biostatistics, The University of Texas MD Anderson Cancer Center, Houston, USA. \\ Email: jlcurry@mdanderson.org
}

Received July $25^{\text {th }}, 2012$; revised August $21^{\text {st }}, 2012$; accepted September $3^{\text {rd }}, 2012$

\begin{abstract}
Melanocytic nevi are a transient in vivo proliferation of melanocytes that after time undergo cellular senescence. Most nevi harbor B-Raf mutations, which appear to activate cellular mechanisms of senescence in melanocytes. Glycogen synthase kinase $3 \beta$ (GSK-3 $\beta$ ), a critical downstream effector of the AKT signaling pathway, is involved in the development of melanoma and has been associated with senescence in melanocytes. Our immunohistochemical and immunofluorescence studies revealed distinct, perinuclear, dot-like reactivity of GSK-3 $\beta$ in melanocytic nevi. Furthermore, our tissue microarray analysis demonstrated significant perinuclear dot-like sublocalization of GSK-3 $\beta$ in melanocytic nevi compared with the amount of GSK-3 $\beta$ observed in melanoma $(P<0.0019)$. In summary, the subcellular localization of GSK- $3 \beta$ in human nevi may contribute to senescence in melanocytes.
\end{abstract}

Keywords: GSK-3 $\beta$; Nevi; Melanoma; Senescence

\section{Introduction}

Cutaneous melanoma, a common skin malignancy with high morbidity and mortality rates, is the second most common form of cancer in women aged 20 - 29 years, and its incidence continues to increase [1,2]. Although melanoma may be surgically curable with early detection, this disease typically becomes resistant to chemotherapy and radiotherapy and progresses unpredictably to more advanced stages [3]. Melanomas may arise in pre-existing nevi or de novo and therefore have a variable clinical presentation. Lesions which are asymmetric, with notched borders, irregular color, diameter greater than $6.0 \mathrm{~mm}$, and evolve over time or "ABCDE" criteria are clinical worrisome features of melanoma requiring biopsy examination [4]. As lesions evolve over time, pigmentation may become more irregular, lesions may develop nodules as tumor grows vertically into the dermis or appear white or regressed in some areas $[4,5]$.

Melanoma typically affects the elderly and middle age to young adults; however, it can occur at any age including children. [6] Melanoma has a higher predilection for fe- males until the age of 40 years and by 75 years of age melanoma is 3 times higher in males than females. Melanoma can occur throughout the body on chronic sun

\footnotetext{
${ }^{*}$ This research is supported in part by the National Institutes of Health through MD Anderson's Cancer Center Support Grant CA016672. \#Corresponding author.
}

exposed sites (head and neck), intermittent sun exposed sites (trunk, legs, and arms) and on body sites with minimal sun exposure (feet and sunugual regions). Melanoma is a heterogeneous disease, arising most frequently through oncogenic mutations in B-raf, $N$-ras, and Kit and with variable exposure to ultraviolet light, depending on the clinical subtype [7].

Cutaneous melanoma is treated by surgical excision. Current recommendations are $0.5 \mathrm{~cm}$ margins for melanoma in situ, $1.0 \mathrm{~cm}$ margins for tumors less than 1.0 $\mathrm{mm}$ in Breslow thickness (BT), and $2.0 \mathrm{~cm}$ surgical margins for tumors of intermediate thickness $(\mathrm{BT}=1-4 \mathrm{~mm})$ and high risk tumors $(\mathrm{BT}>4.0 \mathrm{~mm})$ [8-10]. Lymphatic mapping with sentinel lymph node biopsy is recommended in patients with tumors greater than $1.0 \mathrm{~mm}$ in thickness. Sentinel node positive patients will undergo further lymph node dissection to determine the extent of tumor burden in the regional lymph nodes and for staging [11].

Adjuvant interferon (IFN) alfa therapy combined with surgical excision is approved method of treatment for patients with high-risk melanomas. Patients with advance disease with distant metastasis may be treated with combination of immuno and chemotherapy. Raf inhibitor, vemurafenib has been approved therapy in patients with advanced disease with mutant B-rafV600E tumors [12].

Melanocytic nevi, a transient in vivo proliferation of melanocytes, originate from a transdifferentiation proc- 
ess that allows melanocytes to escape from the early triggers of melanoma development and enter a cellular mechanism of senescence or restricted growth [13]. In the skin, melanocytic nevi are stable neoplasms that become clinically detectable after an initial period of melanocyte proliferation followed by induction of mechanisms of cellular senescence [14]. B-Raf mutations are the most common activating mutations in melanocytic nevi, and overexpression of mutant B-RafV600E induces cell cycle arrest and senescence $[15,16]$. The mechanisms of growth arrest in melanocytic nevi are attributed to several cell cyclin-dependent kinase inhibittors including $\mathrm{p} 16^{\mathrm{INK} 4 \mathrm{a}}, \mathrm{p} 27^{\mathrm{KIP} 1}$, and $\mathrm{p} 57^{\mathrm{KIP} 2}[17,18]$.

Glycogen synthase kinase-3 (GSK-3) is a serine/ threonine protein kinase involved in phosphorylation of the glycogen synthase (GS) [19]. A proportion of GSK-3 is present in an active, multiprotein complex composed of axin, adenomatous polyposis coli (APC) protein, and $\beta$-catenin [20]. GSK-3 $\alpha$ and GSK-3 $\beta$ are the two isoforms of GSK-3 which are structurally similar, but functionally diverse [21]. GSK-3 $\beta$ null mice die in utero since activity of GSK- $3 \alpha$ cannot rescue impaired functions of GSK-3 $\beta$ [22]. GSK-3 $\beta$ has been associated with senescence and melanocyte differentiation and melanogenesis $[23,24]$. GSK- $3 \beta$ is a critical downstream effector of the AKT signaling pathway, which accounts for $10 \%-30 \%$ of melanomas [25]. Primary and metastatic melanomas demonstrate increased expression of phosphorylated $\mathrm{AKT}$, and the identification of AKT mutations in melanoma cell lines supports the role of this signaling pathway in melanomagenesis [26]. Furthermore, animal studies have demonstrated that AKT has the ability to convert melanoma cells from a radial to a vertical growth phase phenotype $[27,28]$. Thus an AKT/GSK-3 $\beta$ pathway may be a crucial component in the sequence of biologic interactions that initiates melanocytes to form nevi or melanoma. To further examine AKT/GSK-3 $\beta$ pathway in melanocytic neoplasm, we sought to examine the immunoreactivity of GSK-3 $\beta$ in melanocytic nevi and melanoma. We sought to examine the immuno-reactivity of GSK-3 $\beta$ in melanocytic nevi and melanoma.

\section{Materials and Methods}

\subsection{Nevi and Melanoma Tissue Samples}

After this study was approved by the University of Texas MD Anderson Cancer Center Institutional Review Board for human subject research, we obtained the following formalin-fixed paraffin-embedded tissues from the archives of the Department of Pathology, Section of Dermatopathology at MD Anderson Cancer Center: 144 melanocytic lesions including benign nevi (10 cases), primary cutaneous melanoma without metastasis (41 cases), primary cutaneous melanoma with metastasis (78 cases), and metastatic melanoma (15 cases). All diagnoses had been rendered by dermatopathologists.

\subsection{Tissue Microarray}

Tissue microarray construction was performed as previously described [29]. Briefly, hematoxylin and eosin (H $\&$ E)-stained sections were reviewed from tissue blocks, and $0.6 \mathrm{~mm}$ or $1.0 \mathrm{~mm}$ cylindrical cores from the selected areas were punched out from donor blocks and inserted into a standard $4.5 \times 2.0 \times 1.0 \mathrm{~cm}$ recipient block with use of a manual tissue arrayer (Beecher Instruments, Silver Spring, MD) with an edge-to-edge distance of 0.10 or $0.15 \mathrm{~mm}$. Care was taken to preserve the original tissue block. At least two tissue cores were taken for each case for a total of 144 cores in four tissue microarrays. Control cases were included in each microbarray. Serial $5-\mu \mathrm{m}$-thick sections of each microarray were cut and stained with $\mathrm{H} \& \mathrm{E}$ to verify presence of lesional cells in the tissue cores.

\subsection{Immunohistochemical Studies}

Immunohistochemical studies were performed as previously described [18]. Briefly, 5- $\mu \mathrm{m}$-thick tissue sections were deparaffinized, rehydrated in a graded series of ethanol, and subjected to heat-induced antigen microwave retrieval (using $10 \mathrm{mM}$ citrate buffer [pH 6.0] and microwaving for 15 minutes). Sections were incubated with primary antibody in a buffer containing $0.1 \%$ bovine serum albumin for 1 hour at room temperature. The following antibodies were used: polyclonal anti-GSK-3 $\beta$ (1:100 dilution, Santa Cruz Biotechnology, Santa Cruz, CA). Subsequent immunostaining was performed by using avidin-biotin immunoperoxidase and/or a micro-polymer technique according to the manufacturer's instructions (Vectastain, Vector Laboratories, Burlingame, CA). Endogenous peroxidase activity was blocked with hydrogen peroxide, and the color was developed with either 3-amino-9-ethyl carbazole or diaminobenzidine (Vectastain, Vector Laboratories) as the chromogen, producing a positive red or brown reaction product, respectively. Sections were counterstained with hematoxylin.

\subsection{Immunofluorescence Studies}

Deparaffinized embedded tissue samples of melanoma and nevi were subjected to a graded series of ethanol washes and antigen microwave retrieval in citrate buffer as described earlier. Tissue sections were blocked in PBS-T in 5\% milk for 30 minutes and incubated with primary antibody in a buffer containing $0.1 \%$ bovine serum albumin for 1 hour at $37^{\circ} \mathrm{C}$. Incubation with appropriate anti-rabbit secondary antibody conjugated with tetramethylrhodamine isothiocyanate or FITC (1:500; 
Santa Cruz Biotechnology, Santa Cruz, CA) in 5\% milk with PBS-T was performed for 1 hour at $37^{\circ} \mathrm{C}$ after three 5-minute washes in FA buffer. After incubation with secondary antibody, three 5-minute washes in 5\% milk with PBS-T were performed. One drop of DAPI (Vector Laboratories) was added to each slide, and after a final wash, the slides were mounted with antifade aqueous mounting media (Thermo Fisher Scientific Inc., Waltham, MA) and examined with a fluorescence microscope.

\subsection{Blocking Studies with GSK-3 $\beta$ Substrate}

Tissue sections were deparaffinized as described earlier and subjected to heat-induced antigen in DAKO Target Retrieval Solution at a high $\mathrm{pH}$ for 20 minutes. Primary antibody $(1: 200)$ and substrate $(1: 100)$ were mixed and incubated for 15 minutes at $37^{\circ} \mathrm{C}$. Sections were incubated with the antibody and substrate mix for 1 hour at $37^{\circ} \mathrm{C}$, and subsequent immunostaining was performed as described earlier.

\subsection{Statistical Analysis}

The pattern and intensity of immunolabeling (diffuse cytoplasmic vs perinuclear) in the tissue samples and tissue microarray were scored by dermatopathologists (JLC and VGP) as $0,1,2$, or 3, corresponding respectively to no labeling, weak, moderate, and strong labeling. The percentage of cells that were positive for GSK-3 $\beta$ was scored from $0 \%$ to $100 \%$. Associations between GSK-3 $\beta$ and categorical variables were examined with use of the Fisher's exact test, Kruskal-Wallis test, or Spearman's correlation coefficient as appropriate. A time-to-event analysis was conducted by using Cox proportional hazards regression models. Survival end points included overall survival duration (measured from the time of diagnosis for the particular specimen assayed until death or last follow-up) and disease-free survival duration (measured from the time of diagnosis until the next event: metastasis, new primary, death, or last follow-up). Results were considered significant if $P$ values were less than 0.05. Individual significance levels were not adjusted for multiple comparisons. All analyses were performed with use of SAS 9.1 software (SAS Institute, Cary, North Carolina).

\section{Results}

\section{Distinct Perinuclear Subcellular Localization of GSK-3 $\beta$ in Melanocytic Nevi}

Benign nevi are composed of growth-arrested melanocytes that have entered cellular senescence in response to activating $B$-raf mutations. Oncogene induction of cyclin-dependent kinase inhibitors such as p16INK4a, $\mathrm{p} 27 \mathrm{KIP} 1$, and p57KIP2 in nevi creates a barrier to further melanocytic proliferation. GSK-3 $\beta$ is a crucial enzyme in many cellular processes, including senescence [30].

Striking perinuclear dot-like reactivity of GSK-3 $\beta$ was detected in all cases of benign nevi by immunohistochemical studies (Figure 1(a)). To better localize GSK-3 $\beta$ immunoreactivity in benign nevi, immunofluorescence studies were performed on paraffin-embedded tissue. The subcellular localization of GSK- $3 \beta$ was found to be in the cytoplasm at a perinuclear location (Figure 1(b)).

Invasive melanoma may be associated with melanocytic nevi; therefore, we next examined GSK-3 $\beta$ in lesions that demonstrated both melanomas and nevi in the same tissue section (Figure 2(a)). The nevus component

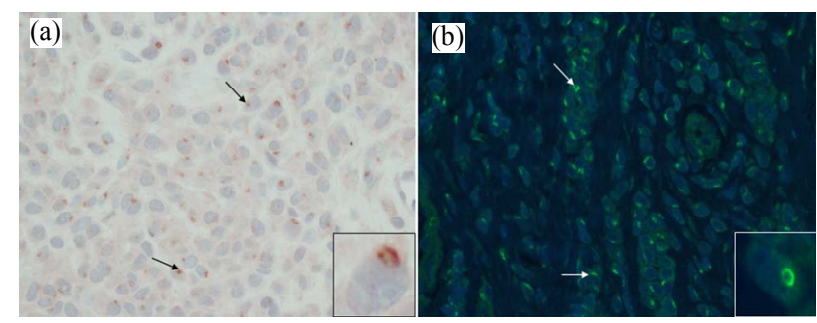

Figure 1. Distinct perinuclear dot-like cytoplasmic immunoreactivity of GSK-3 $\beta$ in benign nevi. (a) GSK-3 $\beta$ immunohistochemical image at $400 \times$ magnification; (b) GSK-3 $\beta$ immunofluorescence image at $400 \times$ magnification. Arrows highlight GSK-3 $\beta$ reactivity in nevus cells. Insert: Subcellular cytoplasmic and perinuclear localization of GSK-3 $\beta$.

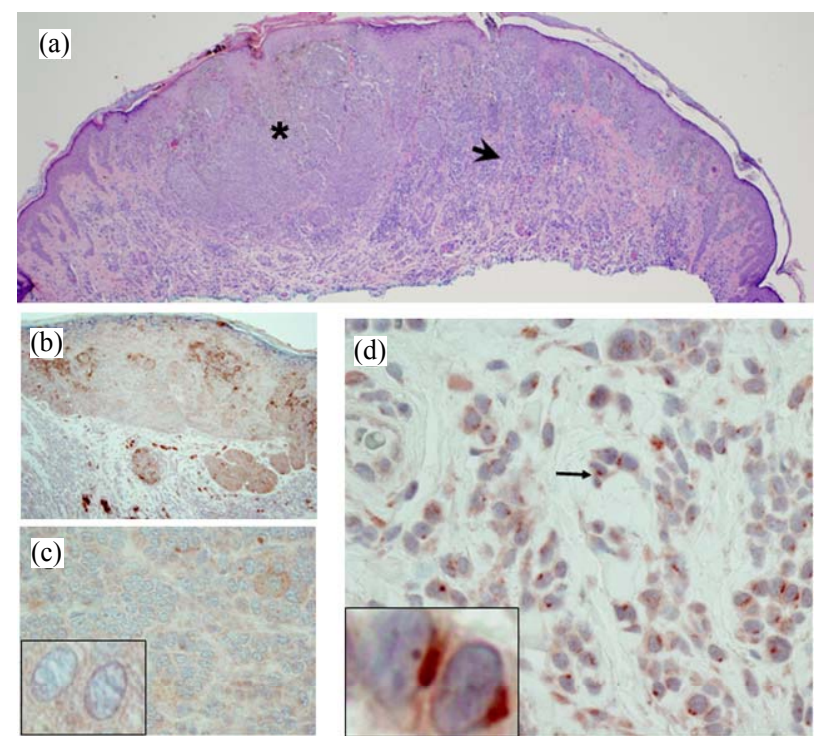

Figure 2. Cytoplasmic reactivity for GSK-3 $\beta$ in cutaneous melanoma. (a) $\mathrm{H} \& \mathrm{E}$-stained image of primary cutaneous melanoma $(*)$ with coexisting benign nevus (short arrow) at 20 $\times$ magnification; (b) GSK-3 $\beta$ immunohistochemical image of invasive melanoma at $200 \times(c)$ and at $400 \times$ magnification. Insert: Absence of cytoplasmic dot-like reactivity for GSK-3 $\beta$ in melanoma cells; (d) Perinuclear GSK-3 $\beta$ reactivity in coexisting nevus cells (long arrow). Insert: Subcellular cytoplasmic and perinuclear localization of GSK-3 $\beta$. 
was composed of banal nevomelanocytes with minimal cytologic atypia and absence of dermal mitoses compared with the invasive melanoma component with enlarged, atypical epithelioid melanoma cells and an increased mitotic rate. Immunohistochemical studies for GSK-3 $\beta$ detected perinuclear labeling in benign nevus cells but not in melanoma cells (Figures 2(b)-(d)).

To ensure that the immunoreactivity was specific to GSK- $3 \beta$, blocking studies with GSK-3 $\beta$ peptide demonstrated decreased perinuclear immunoreactivity for GSK$3 \beta$ in benign melanocytes after the antibody was absorbed with GSK-3 $\beta$ peptide (Figure 3).

We next examined the melanoma tissue microarray for GSK-3 $\beta$ for differences in labeling in nevi and the subgroups of invasive melanoma (melanoma with metastasis, melanoma without metastasis, and metastatic melanoma). The clinical characteristics of the 144 patients in the tissue microarray included median age of 57 years (range 11 to 86 years). The male to female ratio was 1 to 1.1 . Among the patients with melanoma, $69 \%$ of the patients died during follow-up. The estimated median diseasefree survival was 6.2 years (955 CI 5.2 to 7.9 years) and the estimated median overall survival was 6.1 years $(90 \%$ CI 5.1 to 7.8 years). Perinuclear labeling of GSK-3 $\beta$ was greater in melanocytic nevi than it was in melanomas of any subgroup (Figure 4; $P<0.0019$ ). The cytoplasmic percentage of GSK-3 $\beta$ did not vary significantly between nevi and the subgroups of melanoma. The percentage and intensity of GSK-3 $\beta$ immunoreactivity did not appear to be significantly associated with patient age at diagnosis or between histologic factors that included ulceration, Clark level, vertical growth phase, and regression. There was no association between GSK-3 $\beta$ and overall survival.

\section{Discussion}

We have described the presence of GSK-3 $\beta$ in human nevi and melanoma in vivo. Subcellular localization of GSK-3 $\beta$ was detected at significantly higher levels in nevi than in melanoma, although some melanomas did demonstrate perinuclear subcellular localization of GSK$3 \beta$ (data not shown). The expression of GSK-3 $\beta$ (perinuclear or cytoplasmic labeling) in melanoma showed no

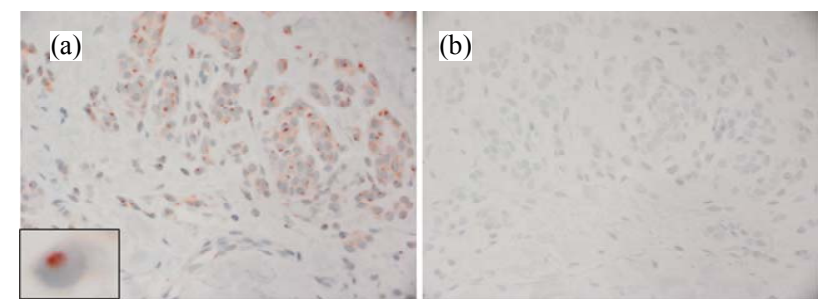

Figure 3. GSK-3 $\beta$ immunohistochemical image in benign nevi at $600 \times$ magnification. ((a) and insert) Dot-like immunoreactivity for GSK-3 $\beta$; (b) GSK-3 $\beta$ immunohistochemical image with blocking peptide at $600 \times$ magnification. Note the absence of immunoreactivity.

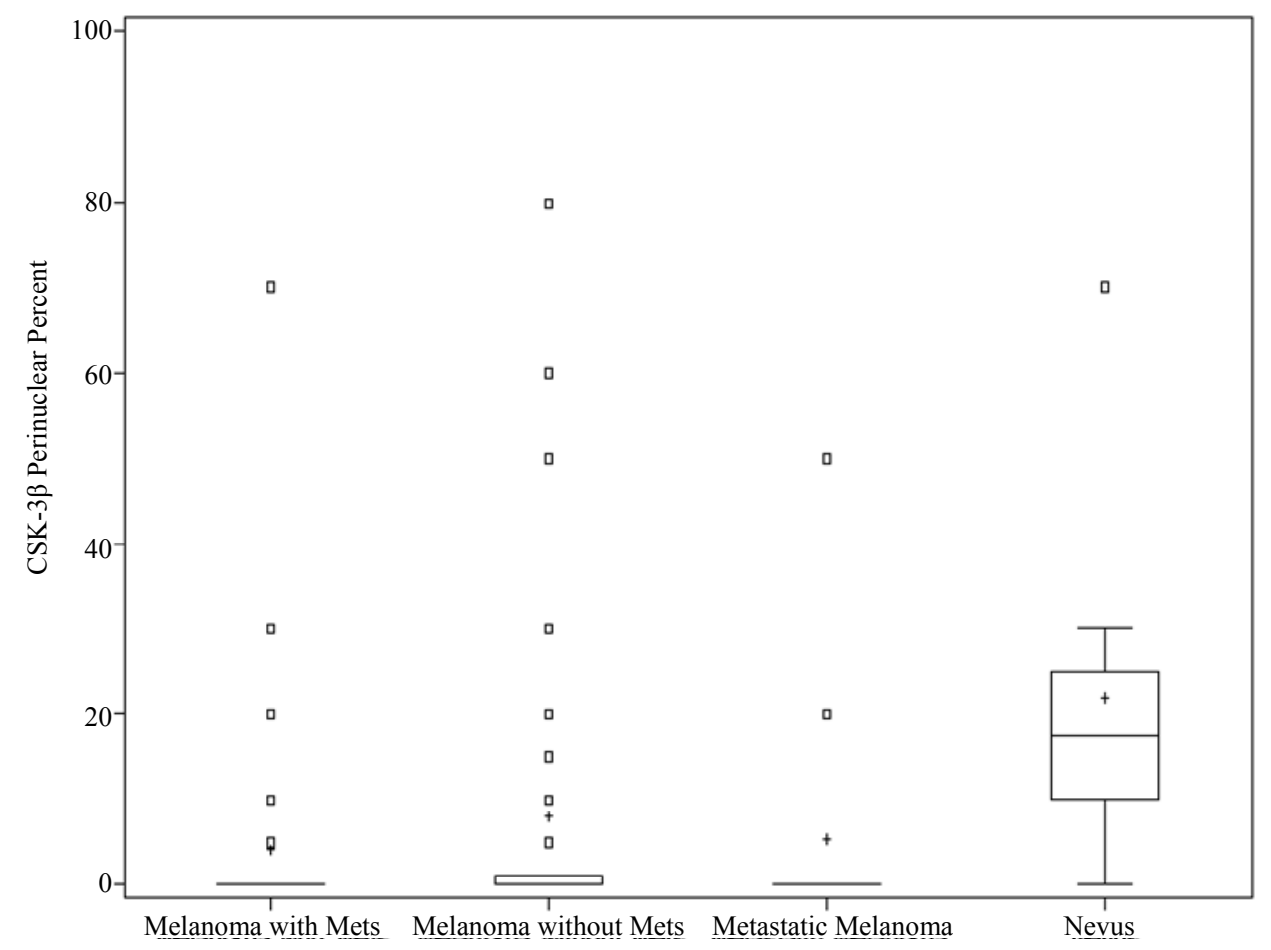

Figure 4. Perinuclear immunoreactivity of GSK-3 $\beta$ in melanoma and nevi. Melanocytic nevi demonstrated higher levels of perinuclear GSK-3 $\beta$ positivity compared with all groups of melanomas. These differences were statistically significant $(P<$ 0.0019). 
correlation with prognostic parameters (e.g., ulceration, tumor thickness, regression, or tumor-infiltrating lymphocytes) in melanoma, metastatic potential, or overall patient survival. However, perinuclear subcellular localization of GSK-3 $\beta$ was more commonly seen in benign nevi, which may have a role in growth arrest of melanocytes.

Regulation of GSK-3 $\beta$ activity is achieved by a combination of inhibitory phosphorylation at the Ser9, protein complex formation, and subcellular localization $[31,32]$. GSK-3 $\beta$ is seen in several subcellular fractions including the cytoplasm, nucleus, and mitochondria [32]. The effects of GSK inhibition promotes GSK- $3 \beta$ mediated phosphorylation and repression of the Wnt signal pathway involved in cell proliferation and carcinogenesis through stabilization of $\beta$-catenin. Activation of AKT inhibits GSK3 through phosphorylation of S21 and S9 residues of GSK- $3 \alpha$ and GSK- $3 \beta$ isoforms, respectively [33]. This inactivation of GSK-3 $\beta$ affects cellular metabolism and allows cellular conversion of glucose into glycogen by glycogen synthase [34,35]. Induction of the senescence phenotype and augmentation of glycogenesis by GSK inhibitors (e.g., SB415286 and $\mathrm{LiCl}$ ) were seen in multiple cell lines including human liver cells, HeLa cells, and primary human diploid fibroblasts. In addition, overexpression of the active GSK-3 $\beta$-S9A mutant could weakly drive senescence with glycogen accumulation [36]. Collectively, these tissue culture studies suggest a potential role for GSK-3 $\beta$ as a regulator of melanocyte senescence.

The subcellular localization of GSK-3 $\beta$ in melanocytic nevi maybe related to protein sequestration (and its inhibition) or compartmentalization of GSK- $3 \beta$ in distinct inactive cellular pools, quality control of the protein, or protein complex formation. GSK- $3 \beta$ is central to many cellular pathways including signaling by insulin, growth factors, cell division, apoptosis, and microtubule formation [20,37]. Insight into the cellular mechanisms of GSK-3 $\beta$ in postnatal expansion of melanocytes in nevogenesis and melanocyte senescence may allow us to combine therapies targeted at induction of senescence along with inhibition of proliferating signals.

\section{Conclusion}

Melanocytic nevi demonstrate distinct peri-nuclear dot like labeling of GSK- $3 \beta$ that was detected by immunohistochemistry and immunofluorescence. Further investigation is necessary to examine the biologic significance of GSK-3 $\beta$ accumulation in melanocytic nevi. In vivo studies with proliferating neonatal human melanocytes and evaluation of phosphorylated GSK-3 $\beta$ in melanocytic neoplasms may provide additional insight into the role of GSK- $3 \beta$ in melanocyte senescence.

\section{Acknowledgements}

We like to thank Dr. Nikolaj Timchenko for kindly providing the use of GSK- $3 \beta$ antibody and Tamara K. Locke for editorial review of the manuscript.

\section{REFERENCES}

[1] A. Jemal, R. Siegel, E. Ward, Y. Hao, J. Xu and M. J. Thun, "Cancer Statistics," Cancer Journal for Clinicians, Vol. 59, No. 4, 2009, pp. 225-249. doi:10.3322/caac.20006

[2] D. S. Rigel, "Epidemiology of Melanoma," Seminars in Cutaneous Medicine and Surgery, Vol. 29, No. 4, 2010, pp. 204-209. doi:10.1016/j.sder.2010.10.005

[3] H. Tsao, M. B. Atkins and A. J. Sober, "Management of Cutaneous Melanoma," New England Journal of Medicine, Vol. 351, 2004, pp. 998-1012.

doi:10.1056/NEJMra041245

[4] N. R. Abbasi, H. M. Shaw, D. S. Rigel, R. J. Friedman, W. H. McCarthy, I. Osman, A. W. Kopf and D. Polsky, "Early Diagnosis of Cutaneous Melanoma: Revisiting the ABCD Criteria," JAMA, Vol. 292, No. 22, 2004, pp. 2771-2776. doi:10.1001/jama.292.22.2771

[5] D. S. Rigel, R. J. Friedman, A. W. Kopf and D. Polsky, "ABCDE-An Evolving Concept in the Early Detection of Melanoma," Archives of Dermatology, Vol. 141, No. 8, 2005, pp. 1032-1034. doi:10.1001/archderm.141.8.1032

[6] S. Paradela, E. Fonseca and V. G. Prieto, "Melanoma in Children," Archives of Pathology \& Laboratory Medicine, Vol. 135, No. 3, 2011, pp. 307-316.

[7] J. A. Curtin, J. Fridlyand, T. Kageshita, H. N. Patel, K. J. Busam, H. Kutzner, K. H. Cho, S. Aiba, E. B. Brocker, P. E. LeBoit, D. Pinkel and B. C. Bastian, "Distinct Sets of Genetic Alterations in Melanoma," New England Journal of Medicine, Vol. 353, No. 20, 2005, pp. 2135-2147. doi:10.1056/NEJMoa050092

[8] NIH Consensus Conference, "Diagnosis and Treatment of Early Melanoma," JAMA, Vol. 268, No. 10, 1992, pp. 1314-1319. doi:10.1001/jama.1992.03490100112037

[9] K. M. Heaton, J. J. Sussman, J. E. Gershenwald, J. E. Lee, D. S. Reintgen, P. F. Mansfield and M. I. Ross, "Surgical Margins and Prognostic Factors in Patients with Thick (>4 mm) Primary Melanoma," Annals of Surgical Oncology, Vol. 5, No. 4, 1998, pp. 322-328. doi:10.1007/BF02303495

[10] P. Gillgren, K. T. Drzewiecki, M. Niin, H. P. Gullestad, H. Hellborg, E. Mansson-Brahme, C. Ingvar and U. Ringborg, "2-cm versus 4-cm Surgical Excision Margins for Primary Cutaneous Melanoma Thicker than $2 \mathrm{~mm}$ : A Randomised, Multicentre Trial," Lancet, Vol. 378, No. 9803, 2011, pp. 1635-1642. doi:10.1016/S0140-6736(11)61546-8

[11] G. M. Boland and J. E. Gershenwald, "Sentinel Lymph Node Biopsy in Melanoma," Cancer Journal, Vol. 18, No. 2, 2012, pp. 185-191. doi:10.1097/PPO.0b013e31825046c7

[12] P. B. Chapman, A. Hauschild, C. Robert, J. B. Haanen, P. Ascierto, J. Larkin, R. Dummer, C. Garbe, A. Testori, M. 
Maio, D. Hogg, P. Lorigan, C. Lebbe, T. Jouary, D. Schadendorf, A. Ribas, S. J. O’Day, J. A. Sosman, J. M. Kirkwood, A. M. Eggermont, B. Dreno, K. Nolop, J. Li, B. Nelson, J. Hou, R. J. Lee, K. T. Flaherty and G. A. McArthur, "Improved Survival with Vemurafenib in Melanoma with BRAF V600E Mutation," New England Journal of Medicine, Vol. 364, No. 26, 2011, pp. 25072516. doi:10.1056/NEJMoa1103782

[13] S. Krengel, "Nevogenesis-New Thoughts Regarding a Classical Problem," American Journal of Dermatopathology, Vol. 27, No. 5, 2005, pp. 456-465. doi:10.1097/01.dad.0000175532.27368.3f

[14] J. V. Schaffer, "Pigmented Lesions in Children: When to Worry," Current Opinion in Pediatrics, Vol. 19, No. 4, 2007, pp. 430-440. doi:10.1097/MOP.0b013e32825b0788

[15] C. Michaloglou, L. C. Vredeveld, M. S. Soengas, C. Denoyelle, T. Kuilman, C. M. van der Horst, D. M. Majoor, J. W. Shay, W. J. Mooi and D. S. Peeper, "BRAFE600-Associated Senescence-Like Cell Cycle Arrest of Human Naevi," Nature, Vol. 436, 2005, pp. 720-724. doi:10.1038/nature03890

[16] P. M. Pollock, U. L. Harper, K. S. Hansen, L. M. Yudt, M. Stark, C. M. Robbins, T. Y. Moses, G. Hostetter, U. Wagner, J. Kakareka, G. Salem, T. Pohida, P. Heenan, P. Duray, O. Kallioniemi, N. K. Hayward, J. M. Trent and P. S. Meltzer, "High Frequency of BRAF Mutations in Nevi," Nature Genetics, Vol. 33, No. 1, 2003, pp. 19-20. doi:10.1038/ng1054

[17] V. C. Gray-Schopfer, S. C. Cheong, H. Chong, J. Chow, T. Moss, Z. A. Abdel-Malek, R. Marais, D. WynfordThomas and D. C. Bennett, "Cellular Senescence in Naevi and Immortalisation in Melanoma: A Role for p16?" British Journal of Cancer, Vol. 95, No. 4, 2006, pp. 496505. doi:10.1038/sj.bjc. 6603283

[18] J. L. Curry, H. W. Richards, Y. T. Huttenbach, E. E. Medrano and J. A. Reed, "Different Expression Patterns of p27 and p57 Proteins in Benign and Malignant Melanocytic Neoplasms and in Cultured Human Melanocytes," Journal of Cutaneous Pathology, Vol. 36, No. 2, 2009, pp. 197-205. doi:10.1111/j.1600-0560.2008.00998.x

[19] N. Embi, D. B. Rylatt and P. Cohen, "Glycogen Synthase Kinase-3 from Rabbit Skeletal Muscle. Separation from Cyclic-AMP-Dependent Protein Kinase and Phosphorylase Kinase," European Journal of Biochemistry, Vol. 107, No. 2, 1980, pp. 519-527. doi:10.1111/j.1432-1033.1980.tb06059.x

[20] P. Cohen and S. Frame, "The renaissance of GSK3," Nature Reviews Molecular Cell Biology, Vol. 2, 2001, pp. 769-776. doi:10.1038/35096075

[21] B. W. Doble and J. R. Woodgett, "GSK-3: Tricks of the Trade for a Multi-Tasking Kinase," Journal of Cell Science, Vol. 116, No. 7, 2003, pp. 1175-1186. doi: $10.1242 /$ jes. 00384

[22] K. P. Hoeflich, J. Luo, E. A. Rubie, M. S. Tsao, O. Jin and J. R. Woodgett, "Requirement for Glycogen Synthase Kinase-3beta in Cell Survival and NF-kappaB Activation," Nature, Vol. 406, No. 6791, 2000, pp. 86-90. doi:10.1038/35017574

[23] Y. H. Seo, H. J. Jung, H. T. Shin, Y. M. Kim, H. Yim, H.
Y. Chung, I. K. Lim and G. Yoon, "Enhanced Glycogenesis Is Involved in Cellular Senescence via GSK3/GS Modulation," Aging Cell, Vol. 7, No. 6, 2008, pp. 894907. doi:10.1111/j.1474-9726.2008.00436.x

[24] B. Bellei, E. Flori, E. Izzo, V. Maresca and M. Picardo, "GSK3beta Inhibition Promotes Melanogenesis in Mouse B16 Melanoma Cells and Normal Human Melanocytes," Cellular Signalling, Vol. 20, No. 10, 2008, pp. 17501761. doi:10.1016/j.cellsig.2008.06.001

[25] F. G. Haluska, H. Tsao, H. Wu, F. S. Haluska, A. Lazar and V. Goel, "Genetic Alterations in Signaling Pathways in Melanoma," Clinical Cancer Research, Vol. 12, No. 7, 2006, pp. 2301s-2307s. doi:10.1158/1078-0432.CCR-05-2518

[26] M. A. Davies, K. Stemke-Hale, C. Tellez, T. L. Calderone, W. Deng, V. G. Prieto, A. J. Lazar, J. E. Gershenwald and G. B. Mills, "A Novel AKT3 Mutation in Melanoma Tumours and Cell Lines," British Journal of Cancer, Vol. 99, No. 8, 2008, pp. 1265-1268. doi:10.1038/sj.bjc. 6604637

[27] B. Govindarajan, J. E. Sligh, B. J. Vincent, M. Li, J. A. Canter, B. J. Nickoloff, R. J. Rodenburg, J. A. Smeitink, L. Oberley, Y. Zhang, J. Slingerland, R. S. Arnold, J. D. Lambeth, C. Cohen, L. Hilenski, K. Griendling, M. Martinez-Diez, J. M. Cuezva and J. L. Arbiser, "Overexpression of Akt Converts Radial Growth Melanoma to Vertical Growth Melanoma," The Journal of Clinical Investigation, Vol. 117, No. 3, 2007, pp. 719-729. doi:10.1172/JCI30102

[28] D. L. Dai, M. Martinka and G. Li, "Prognostic Significance of Activated Akt Expression in Melanoma: A Clinicopathologic Study of 292 Cases," Journal of Clinical Oncology, Vol. 23, No. 7, 2005, pp. 1473-1482. doi:10.1200/JCO.2005.07.168

[29] V. G. Prieto, A. A. Mourad-Zeidan, V. Melnikova, M. M. Johnson, A. Lopez, A. H. Diwan, A. J. Lazar, S. S. Shen, P. S. Zhang, J. A. Reed, J. E. Gershenwald, A. Raz and M. Bar-Eli, "Galectin-3 Expression Is Associated with Tumor Progression and Pattern of Sun Exposure in Melanoma," Clinical Cancer Research, Vol. 12, No. 22, 2006, pp. 6709-6715. doi:10.1158/1078-0432.CCR-06-0758

[30] J. W. Zmijewski and R. S. Jope, "Nuclear Accumulation of Glycogen Synthase Kinase-3 during Replicative Senescence of Human Fibroblasts," Aging Cell, Vol. 3, 2004, pp. 309-317. doi:10.1111/j.1474-9728.2004.00117.x

[31] D. M. Ferkey and D. Kimelman, "GSK-3: New Thoughts on an Old Enzyme," Developmental Biology, Vol. 225, No. 2, 2000, pp. 471-479. doi:10.1006/dbio.2000.9816

[32] G. N. Bijur and R. S. Jope, "Rapid Accumulation of Akt in Mitochondria Following Phosphatidylinositol 3-Kinase Activation," Journal of Neurochemistry, Vol. 87, No. 6, 2003, pp. 1427-1435. doi:10.1046/j.1471-4159.2003.02113.x

[33] C. Sutherland, I. A. Leighton and P. Cohen, "Inactivation of Glycogen Synthase Kinase-3 Beta by Phosphorylation: New Kinase Connections in Insulin and Growth-Factor Signalling," Biochemical Journal, Vol. 296, Pt. 1, 1993, pp. 15-19.

[34] D. M. Ferkey and D. Kimelman, "Glycogen Synthase 
Kinase-3 Beta Mutagenesis Identifies a Common Binding Domain for GBP and Axin," Journal of Biological Chemistry, Vol. 277, No. 18, 2002, pp. 16147-16152. doi:10.1074/jbc.M112363200

[35] S. R. Datta, A. Brunet and M. E. Greenberg, "Cellular Survival: A Play in Three Akts," Genes \& Development, Vol. 13, 1999, pp. 2905-2927. doi:10.1101/gad.13.22.2905

[36] S. J. Lee, Y. H. Chung, K. M. Joo, H. C. Lim, G. S. Jeon,
D. Kim, W. B. Lee, Y. S. Kim and C. I. Cha, "Age-Related Changes in Glycogen Synthase Kinase 3beta (GSK3beta) Immunoreactivity in the Central Nervous System of Rats," Neuroscience Letters, Vol. 409, No. 2, 2006, pp. 134-139. doi:10.1016/j.neulet.2006.09.026

[37] S. Frame and P. Cohen, "GSK3 Takes Centre Stage More than 20 Years after Its Discovery," Biochemical Journal, Vol. 359, No. 1, 2001, pp. 1-16. doi:10.1042/0264-6021:3590001 